\title{
BMJ
}

\section{Coronary heart disease mortality among young adults in Scotland in relation to social inequalities: time trend study}

Martin O'Flaherty, MRC research fellow, ${ }^{1}$ Jennifer Bishop, programme principal ScotPHO , ${ }^{2}$ Adam Redpath, programme principal for CHD and stroke programme, ${ }^{2}$ Terry McLaughlin, senior information analyst, ${ }^{2}$ David Murphy, senior information analyst, ${ }^{2}$ James Chalmers, consultant in public health, ${ }^{2}$ Simon Capewell, professor of clinical epidemiology ${ }^{1}$

${ }^{1}$ Division of Public Health, University of Liverpool, Liverpool L69 3GB

${ }^{2}$ ISD Scotland, Edinburgh EH12 9ED

Correspondence to: S Capewell capewell@liverpool.ac.uk

Cite this as: $B M J$ 2009;339:b2613 doi:10.1136/bmj.b2613

\section{ABSTRACT}

Objective To examine recent trends and social inequalities in age specific coronary heart disease mortality.

Design Time trend analysis using joinpoint regression. Setting Scotland, 1986-2006.

Participants Men and women aged 35 years and over. Main outcome measures Age adjusted and age, sex, and deprivation specific coronary heart disease mortality. Results Persistent sixfold social differentials in coronary heart disease mortality were seen between the most deprived and the most affluent groups aged 35-44 years. These differentials diminished with increasing age but equalised only above 85 years. Between 1986 and 2006, overall, age adjusted coronary heart disease mortality decreased by $61 \%$ in men and by $56 \%$ in women. Among middle aged and older adults, mortality continued to decrease fairly steadily throughout the period. However, coronary heart disease mortality levelled from 1994 onwards among young men and women aged 35-44 years. Rates in men and women aged 45-54 showed similar flattening from about 2003. Rates in women aged 55-64 may also now be flattening. The flattening of coronary heart disease mortality in younger men and women was confined to the two most deprived fifths.

Conclusions Premature death from coronary heart disease remains a major contributor to social inequalities. Furthermore, the flattening of the decline in mortality for coronary heart disease among younger adults may represent an early warning sign. The observed trends were confined to the most deprived groups. Marked deterioration in medical management of coronary heart disease seems implausible. Unfavourable trends in the major risk factors for coronary heart disease (smoking and poor diet) thus provide the most likely explanation for these inequalities.

\section{INTRODUCTION}

Scotland has seen a halving of mortality from coronary heart disease in the past two decades. ${ }^{1}$ However, cardiovascular mortality in this country is still among the highest in Europe and globally. ${ }^{2}$ In other countries with high but declining coronary heart disease mortality, several reports suggest that these trends are changing. ${ }^{3-6}$ Slowing or flattening of the decline in coronary heart disease mortality in young adults has now been reported in England and Wales, ${ }^{5}$ the United States ${ }^{6}$ France, Australia, ${ }^{3}$ and New Zealand. ${ }^{4}$

The pattern for trends in major cardiovascular risk factors is also changing, with dramatic increases in obesity and diabetes in all industrialised countries, ${ }^{7}$ flattening of falls in blood pressure in US women, ${ }^{8}$ and persistent smoking in young adults in the United Kingdom and elsewhere. ${ }^{9}$ Recent trends in cardiovascular risk factors among Scottish adults present a correspondingly complex picture. Considerable progress was seen between 1997 and 2003, with decreases in physical inactivity, dietary intake of fat and salt, and smoking (which reached government targets set for 2010).${ }^{10}$ However, recent substantial rises in obesity and diabetes among young adults raise concerns about subsequent increases in their coronary heart disease mortality. ${ }^{11}$

Because most cardiovascular risk factors are powerfully associated with socioeconomic deprivation, ${ }^{12}$ we hypothesised that if any deterioration in mortality in young adults was occurring this would be seen particularly in the most materially deprived people. We therefore examined recent trends and social inequalities in age specific coronary heart disease mortality in Scotland, particularly among disadvantaged younger adults.

\section{METHODS}

Mortality statistics and socioeconomic status data

We obtained data on vital statistics for the Scottish population for the period 1986-2006. We limited our analyses to people aged 35 years and older. We determined underlying cause of death from coronary heart disease by using ICD-9 (International Classification of Diseases, ninth revision) codes 410-414 for 1986-98 and ICD-10 codes I20-I25 for 1999-2006. We adjusted data for age by using the direct method to the European standard population. ${ }^{13}$ 


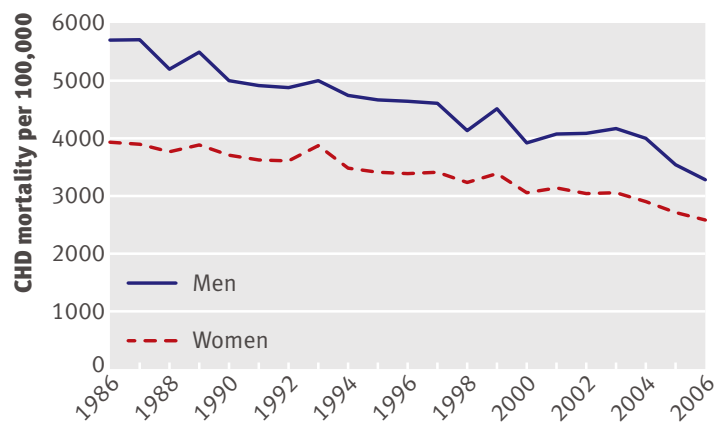

Fig 1 1 Age standardised coronary heart disease mortality in Scotland by sex, 1986-2006

We categorised area level socioeconomic status by using Scottish Index of Multiple Deprivation (SIMD) fifths for 2006. The SIMD is the Scottish Executive's official measure of area based multiple deprivation. It is based on 31 indicators in six individual domains (current income; employment; housing; health; education, skills, and training; and geographical access to services and telecommunications). The SIMD is calculated at the level of data zones (median population size of 770), enabling small pockets of deprivation to be identified. The data zones are ranked from most deprived (1) to least deprived (6505) on the overall SIMD index. The result is a detailed and comprehensive picture of relative area deprivation across Scotland. We report SIMD in fifths; the first and second fifths are the least deprived, and the fourth and fifth are the most deprived. ${ }^{14}$ As the SIMD health domain for 2000-4 includes a mortality indicator, the comparative mortality factor, this risks a tautology. We therefore repeated our analyses with only the income component of the SIMD. We obtained data on coronary heart disease mortality by age and sex for the

\begin{tabular}{|c|c|c|c|}
\hline $\begin{array}{l}\text { Age group (years) } \\
\text { and identified periods }\end{array}$ & $\begin{array}{l}\text { No of deaths } \\
\text { (min-max) }\end{array}$ & $\begin{array}{l}\text { Rates per } 106 \\
\quad(\min -\max )\end{array}$ & $\begin{array}{l}\text { Annual percentage change } \\
\qquad(95 \% \mathrm{Cl})\end{array}$ \\
\hline \multicolumn{4}{|l|}{ 35-54: } \\
\hline $1986-2003$ & $434-955$ & $60.3-157$ & $-6.28 *(-6.76$ to -5.80$)$ \\
\hline $2003-6$ & $425-449$ & $58.6-61.7$ & $-0.55(-9.47$ to 9.24$)$ \\
\hline \multicolumn{4}{|l|}{ 55-64: } \\
\hline 1986-97 & $1227-2152$ & $483-826$ & $-4.78^{*}(-5.35$ to -4.22$)$ \\
\hline $1997-2006$ & $743-1129$ & $244-439$ & $-8.81^{*}(-9.82$ to -7.78$)$ \\
\hline \multicolumn{4}{|l|}{ 65-74: } \\
\hline $1986-93$ & $3003-3380$ & $1523-1833$ & $-3.72 *(-4.57$ to -2.86$)$ \\
\hline $1993-9$ & $2190-2916$ & $1106-1455$ & $-5.54^{\star}(-7.13$ to -3.92$)$ \\
\hline 1999-2006 & $1248-1946$ & $599-978$ & $-7.89 *(-9.08$ to -6.68$)$ \\
\hline \multicolumn{4}{|l|}{ 75-84: } \\
\hline $1986-94$ & $2835-2967$ & $2763-3263$ & $-1.77^{\star}(-2.74$ to -0.79$)$ \\
\hline $1994-2006$ & $1692-1627$ & $1492-2717$ & $-6.59^{\star}(-7.20$ to -5.97$)$ \\
\hline \multicolumn{4}{|l|}{$\geq 85$ : } \\
\hline $1986-98$ & $710-941$ & 4123-5696 & $-6.52 *(-7.16$ to -5.86$)$ \\
\hline $1998-2003$ & $890-992$ & $3931-4508$ & $-2.21(-6.09$ to 1.83$)$ \\
\hline $2003-6$ & $895-918$ & $895-3989$ & $-11.14^{*}(-17.10$ to -4.74$)$ \\
\hline
\end{tabular}
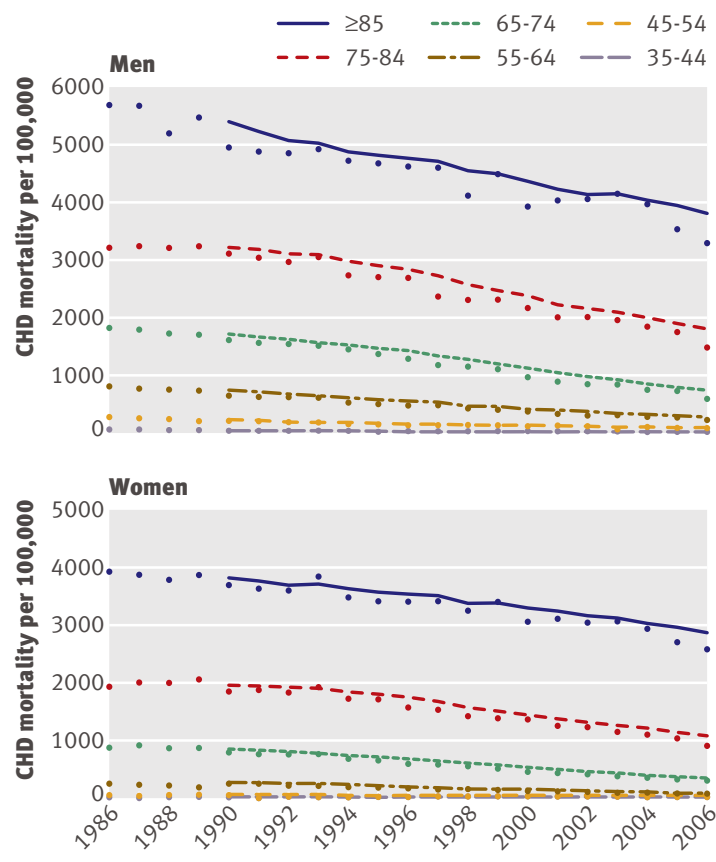

Fig 2 | Age specific coronary heart disease mortality trends in men and women (Scotland 1986-2006)

period 1986-2006 and SIMD data for the period 1996-2006.

\section{Trend analysis}

We used five year moving averages to smooth plots of mortality and plots of annual absolute changes in the age specific mortality. We fitted a joinpoint regression to provide estimated annual percentage change and to detect points in time at which significant changes in the trends occurred (Joinpoint Regression Program, version 3.0). This technique identifies periods of mortality data with similar rates of change. This process uses a series of permutation tests, adjusted for multiple comparisons, and thus avoids bias from arbitrarily defining the periods. We used a bayesian information criterion approach to select the most parsimonious model that best fitted the data. We allowed a maximum of three joinpoints for estimations. For each estimate of annual percentage change, we also calculated the corresponding 95\% confidence interval. We did two joinpoint regression analyses. The first covered the period 1986-2006 for age and sex specific coronary heart disease mortality alone, and the second covered the period 1996-2006 for sex, age, and deprivation specific coronary heart disease mortality (as this was the period for which deprivation data were available). To increase statistical power for these last analyses, we then combined the deprivation data into three groups: the two most deprived fifths (4 and 5), the intermediate fifth (3), and the two least deprived fifths (1 and 2).

\section{RESULTS}

Age adjusted trends in coronary heart disease mortality Between 1986 and 2006 age adjusted mortality from coronary heart disease decreased overall by $60.9 \%$ in 
Table 2 |Coronary heart disease mortality trends by age in Scotland 1986-2006: joinpoint analysis in women aged 35 years and over

\begin{tabular}{|c|c|c|c|}
\hline $\begin{array}{l}\text { Age group (years) } \\
\text { and identified periods }\end{array}$ & $\begin{array}{l}\text { No of deaths } \\
\text { (min-max) }\end{array}$ & $\begin{array}{l}\text { Rates per } 106 \\
(\min -\max )\end{array}$ & $\begin{array}{l}\text { Annual percentage change } \\
\qquad(95 \% \mathrm{Cl})\end{array}$ \\
\hline \multicolumn{4}{|l|}{ 35-54: } \\
\hline $1986-9$ & $197-223$ & $31.5-35.6$ & $0.14(-6.96$ to 7.78$)$ \\
\hline $1989-95$ & $139-198$ & $20.3-30.6$ & $-9.02^{\star}(-12.31$ to -5.60$)$ \\
\hline $1995-2006$ & $102-154$ & $13.2-21.8$ & $-4.94^{*}(-6.24$ to -3.61$)$ \\
\hline \multicolumn{4}{|l|}{ 55-64: } \\
\hline $1986-91$ & $722-807$ & $254-280$ & $-2.00(-4.00$ to 0.03$)$ \\
\hline $1991-9$ & $387-612$ & $137-217$ & $-6.99^{*}(-8.37$ to -5.60$)$ \\
\hline 1999-2006 & $245-369$ & $78-130$ & $-9.79 *(-11.59$ to -7.95$)$ \\
\hline \multicolumn{4}{|l|}{ 65-74: } \\
\hline $1986-9$ & $2127-2258$ & $851-899$ & $-1.28(-4.2$ to 2.49$)$ \\
\hline $1989-98$ & $1342-1947$ & $542-785$ & $-4.81^{*}(-5.70$ to -3.92$)$ \\
\hline $1998-2006$ & $724-1253$ & $293-509$ & $-7.38^{*}(-8.52$ to -6.24$)$ \\
\hline \multicolumn{4}{|l|}{ 75-84: } \\
\hline $1986-93$ & $3047-3477$ & $1830-2055$ & $-0.27(-1.38$ to 0.84$)$ \\
\hline 1993-2006 & $1560-2738$ & $898-1706$ & $-5.42^{\star}(-5.92$ to -4.92$)$ \\
\hline \multicolumn{4}{|l|}{$\geq 85:$} \\
\hline $1986-98$ & $1735-2200$ & $3245-3913$ & $-4.28^{\star}(-4.82$ to -3.75$)$ \\
\hline $1998-2003$ & $1936-2177$ & $3039-3394$ & $-1.25(-4.36$ to 1.97$)$ \\
\hline 2003-6 & $1756-1818$ & $2581-2921$ & $-6.76^{\star}(-11.72$ to -1.52$)$ \\
\hline
\end{tabular}

*Significantly different from $0 \%$.
However, no narrowing of the relative inequality gap occurred (fig 5). Coronary heart disease mortality in men aged 35-54 in the two most deprived fifths decreased between 1996 and 2004 (annual percentage change $-5.62 \%,-6.88$ to -4.34 ) (table 3). Furthermore, the annual percentage change between 2004 and 2006 was not significantly different from 0 , (point estimate $6.4 \%,-6.72$ to 21.38 ). In men and women aged up to 75 years, the annual percentage changes were consistently smaller in the most deprived fifths compared with the most affluent fifths (tables 3 and 4). We found similar results when we repeated the analyses with the SIMD income component alone.

\section{DISCUSSION}

The overall decline in age standardised mortality from coronary heart disease conceals a flattening in younger men and women in Scotland similar to that reported in England and Wales and in the United States. Furthermore, in Scotland, the rate of decline between 1996 and 2006 in young men and women aged under 54 years was significantly slower in the most deprived groups than in the most affluent groups. Sixfold social differentials in coronary heart disease mortality were apparent in Scotland between 1986 and 2005; these differentials disappeared only above the age of 85 years.

men and by $56.4 \%$ in women (fig 1 ). The average rate of decline in men was $-2.88 \%$ (95\% confidence interval $-3.86 \%$ to $-1.89 \%$ ) between 1986 and 1993 and $-5.03 \%(-5.40 \%$ to $-4.65 \%)$ for the period 1993 2006. For women, the average rate of decline was $-2.23 \%(-3.11 \%$ to $-1.34 \%)$ for $1986-93$ and $-5.04 \%$ $(-5.37 \%$ to $-4.70 \%)$ for $1993-2006$.

Age and sex specific trends in coronary heart disease mortality

Age specific rates showed a more complex picture (fig 2). In both men and women aged over 55, the annual percentage change increased between 1986 and 2006. However, in men and women under 55, clear decreases occurred in the annual percentage change. Men aged 35-54 showed significant flattening after 2003. Furthermore, the annual percentage change for that period $(-0.55 \%, 95 \%$ confidence interval -9.47 to 9.24 ) was not significantly different from 0\% (table 1). Likewise, in women aged 35-54 the annual percentage change was $-9.02 \%$ in $1989-95$ and decreased to $-4.94 \%$ in $1995-2006$, suggesting that the rate of decline is slowing down significantly in young women (table 2).

Socioeconomic differentials in coronary heart disease mortality trends

We found sixfold socioeconomic differentials between coronary heart disease mortality in the most deprived and most affluent fifths (fig 3). Although these differentials decreased with greater age, they disappeared only above 85 years (fig 4).

Age standardised mortality across most fifths of deprivation decreased between 1996 and 2006 (fig 3). 

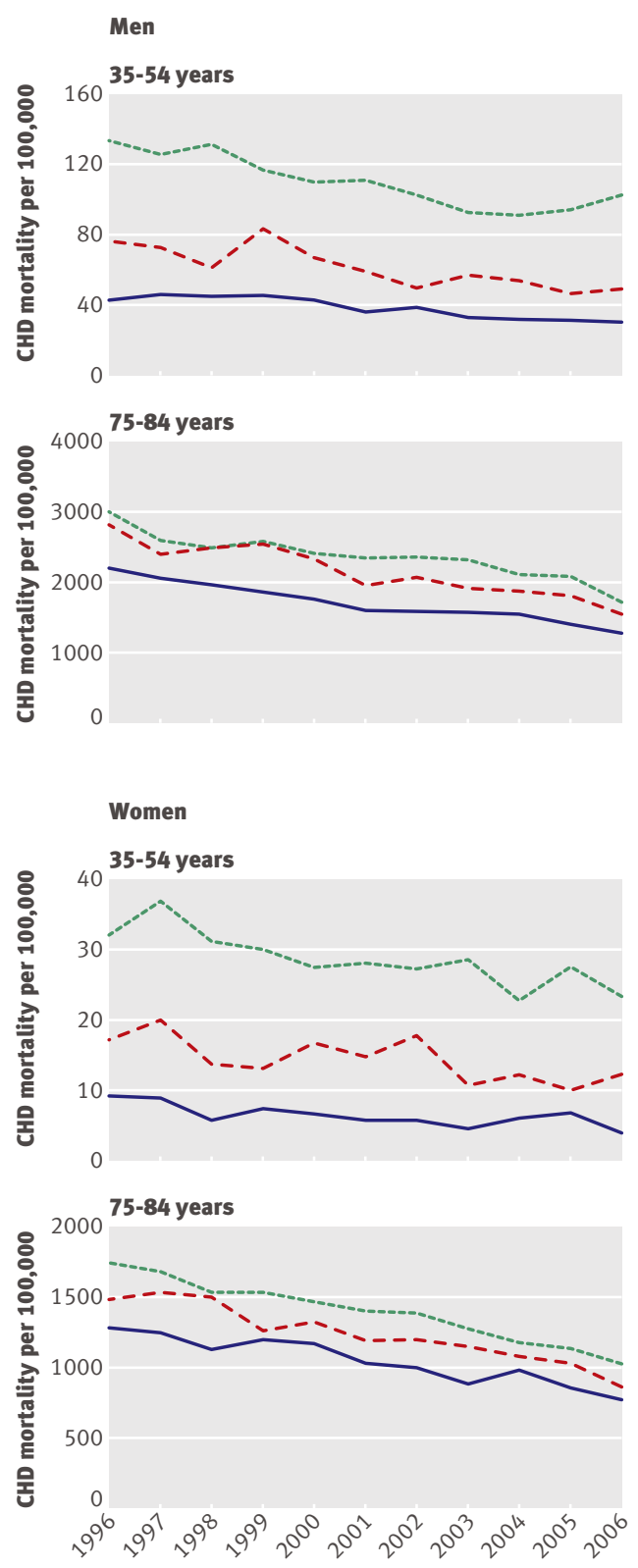
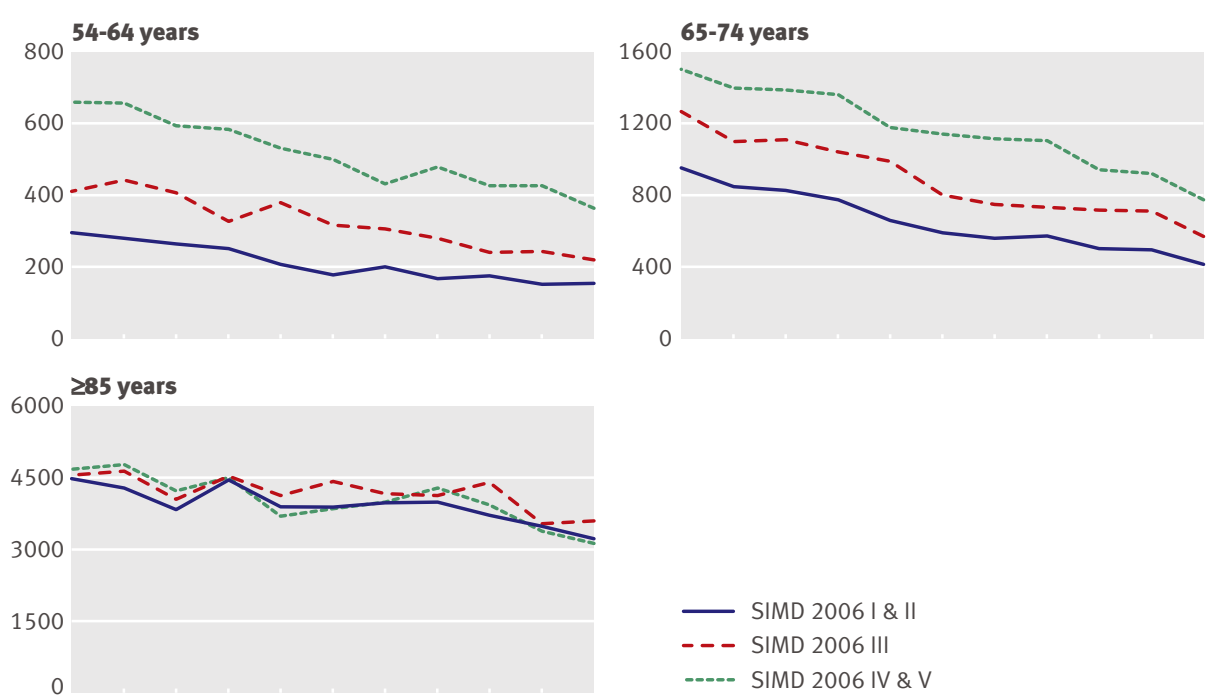

- - SIMD 2006 III

-...- SIMD 2006 IV \& V
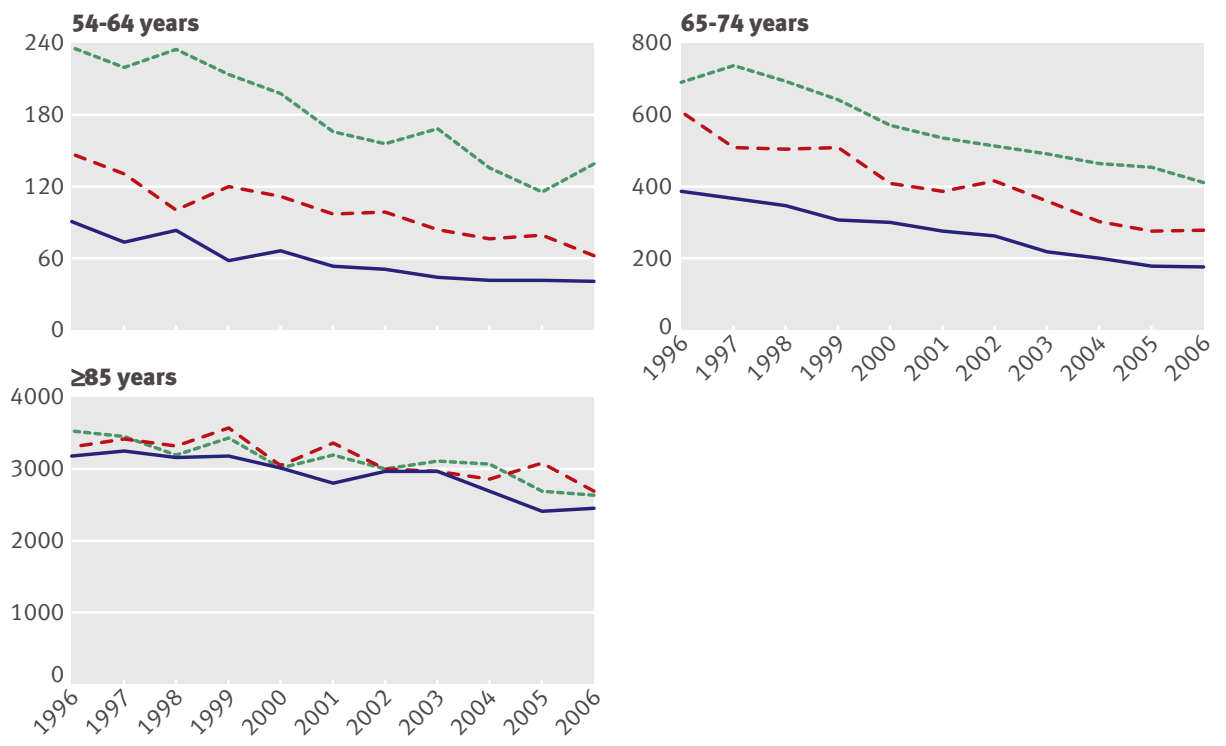

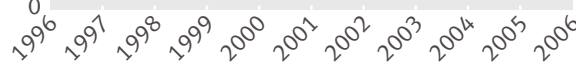

Fig 4 | Coronary heart disease mortality trends by age and deprivation in men and women (Scotland 1996-2006). SIMD=Scottish Index of Multiple Deprivation

\section{Strengths and limitations}

This analysis has several strengths. The joinpoint regression analysis is able to identify periods of similar annual percentage change; this avoids the need to prespecify time periods (which may then bias the way in which the trends are analysed). Moreover, because we deliberately limited the maximum number of possible joinpoints in this study, each estimate of annual percentage change was based on more individual years than would otherwise have been the case.

However, such analyses also have limitations. As most of the changes in trend were recent, the confidence intervals for the average annual percentage changes were correspondingly wider. The significance of these changes should therefore not be overstated. The point estimate suggests an increase in coronary heart disease mortality in young men. However, the wide confidence interval encompassing zero simply means that a flat line is possible. This potentially important observation needs to be confirmed in other populations. Similar constraints apply when comparing rates of decline between social groups.

Although the quality of data for registration of mortality was not perfect, the potential for disproportionate miscoding of mortality in deprived areas over a short time seems very small. Furthermore, several studies suggest that coding in coronary heart disease is of good quality in young adults, extending up to and beyond the age of $65 .^{15-17}$

Measuring deprivation is a complex task. Although the SIMD may not be perfect, it is probably at least as good a measure of deprivation as the Carstairs and Townsend indices. ${ }^{1819}$ Because the SIMD health domain included an indicator of the comparative 
Table 3 |Joinpoint analysis of coronary heart disease mortality trends by age and deprivation in Scotland 1996-2006: men aged 35 years and over

\begin{tabular}{|c|c|c|c|c|}
\hline $\begin{array}{l}\text { Age group (years) and } \\
\text { deprivation category }\end{array}$ & $\begin{array}{l}\text { Identified } \\
\text { periods }\end{array}$ & $\begin{array}{l}\text { No of deaths } \\
\text { (min-max) }\end{array}$ & $\begin{array}{l}\text { Rates per } 105 \\
(\min -\max )\end{array}$ & $\begin{array}{l}\text { Annual percentage change } \\
\qquad(95 \% \mathrm{Cl})\end{array}$ \\
\hline \multicolumn{5}{|l|}{ 35-54: } \\
\hline \multirow{2}{*}{1 and 2 (most affluent) } & $1996-8$ & $50-82$ & $33-57$ & $2.47(-14.87$ to 23.35$)$ \\
\hline & $1998-2006$ & $39-83$ & $25-57$ & $-6.46^{*}(-8.53$ to -4.34$)$ \\
\hline 3 & $1996-2006$ & $69-116$ & $47-82$ & $-5.64^{\star}(-7.80$ to -3.42$)$ \\
\hline \multirow[t]{2}{*}{4 and 5 (most deprived) } & 1996-2004 & $87-210$ & $65-167$ & $-5.62^{\star}(-6.88$ to -4.34$)$ \\
\hline & 2004-6 & $103-158$ & $75-123$ & 6.40 (-6.72 to 21.38$)$ \\
\hline \multicolumn{5}{|l|}{ 55-64: } \\
\hline 1 and 2 (most affluent) & $1996-2006$ & $72-152$ & 131-313 & $-10.44^{*}(-11.59$ to -9.27$)$ \\
\hline 3 & 1996-2006 & $145-233$ & $225-442$ & $-9.65^{*}(-11.26$ to -8.01$)$ \\
\hline 4 and 5 (most deprived) & 1996-2006 & $170-455$ & 295-803 & $-5.58^{*}(-6.51$ to -4.65$)$ \\
\hline \multicolumn{5}{|l|}{ 65-74: } \\
\hline 1 and 2 (most affluent) & 1996-2006 & $143-376$ & $368-1028$ & $-9.43^{*}(-10.24$ to -8.62$)$ \\
\hline 3 & 1996-2006 & 261-532 & $583-1279$ & $-7.69 *(-8.79$ to -6.59$)$ \\
\hline \multirow{2}{*}{4 and 5 (most deprived) } & $1996-2003$ & 411-704 & $959-1610$ & $-3.98^{\star}(-5.59$ to -2.33$)$ \\
\hline & $2003-6$ & $309-430$ & $727-1075$ & $-8.58^{\star}(-15.43$ to -1.18$)$ \\
\hline \multicolumn{5}{|l|}{ 75-84: } \\
\hline 1 and 2 (most affluent) & 1996-2006 & $250-402$ & $1204-2247$ & $-8.29 *(-8.78$ to -7.80$)$ \\
\hline 3 & 1996-2006 & $373-560$ & $1550-2804$ & $-6.83^{\star}(-7.94$ to -5.72$)$ \\
\hline 4 and 5 (most deprived) & 1996-2006 & $366-603$ & $1646-3080$ & $-4.63^{\star}(-5.75$ to -3.50$)$ \\
\hline \multicolumn{5}{|l|}{$\geq 85:$} \\
\hline \multirow{2}{*}{1 and 2 (most affluent) } & 1996-2004 & $144-214$ & $3467-4658$ & $-4.30 *(-6.43$ to -2.12$)$ \\
\hline & $2004-6$ & $162-200$ & $3164-3688$ & $-13.30(-31.12$ to 9.13$)$ \\
\hline \multirow{3}{*}{3} & $1996-8$ & $187-207$ & 4081-4698 & $-8.66(-24.09$ to 9.90$)$ \\
\hline & $1998-2004$ & $203-218$ & 4166-4545 & $-1.22(-5.36$ to 3.11$)$ \\
\hline & $2004-6$ & $145-183$ & $3152-3500$ & $-15.99(-31.91$ to 3.65$)$ \\
\hline \multirow{3}{*}{4 and 5 (most deprived) } & $1996-2000$ & $142-209$ & $3633-4991$ & $-8.49^{\star}(-14.25$ to -2.34$)$ \\
\hline & $2000-4$ & $145-200$ & $3152-3500$ & $1.24(-9.23$ to 12.91$)$ \\
\hline & 2004-6 & $145-179$ & $3923-4501$ & $-19.96(-37.21$ to 2.00$)$ \\
\hline
\end{tabular}

*Significantly different from $0 \%$. slower than that in more advantaged people in the period $1983-93 .^{20}$ In the United States, the rate of decline in heart disease and stroke mortality among the least educated people was slower than in others, particularly in African Americans with low educational levels. ${ }^{21}$ In New Zealand, a cohort effect has been suggested, with flattening of the observed decline in mortality and a predicted major increase in burden for Maoris and Pacific Islanders (both relatively deprived compared with people of European origin). ${ }^{4}$

\section{Possible explanations}

Why might this flattening of the decline in mortality remain confined to the most deprived groups? Several possible explanations should be considered. Firstly, the distribution of major cardiovascular risk factors in the Scottish population showed marked socioeconomic gradients. ${ }^{11}$ These "downstream" biological risk factors such as smoking, cholesterol, and blood pressure will in turn be strongly patterned by "upstream" socioeconomic factors such as low educational attainment, poor housing, and inadequate income. Thus in Finland, where substantial decreases in cardiovascular mortality have occurred in the past four decades, changes in risk factors are a stronger explanation for the decline in mortality among the low socioeconomic groups compared with the more affluent ones. ${ }^{22}$

Different levels and rates of change for cardiovascular risk factors in different socioeconomic groups may therefore make an important contribution to the continuing inequalities in mortality from coronary heart disease. ${ }^{123}$ In Scotland, the rate of smoking in

mortality factor for 2000-4, we had to be cautious when analysing mortality data in case a tautology occurred. However, our results were essentially unchanged when we repeated the analyses with only the income component of the SIMD as the deprivation measure. Likewise, the SIMD 2006 may not accurately reflect deprivation during the entire period of our analysis.

A slowing of the rate of decline might simply reflect extremely low rates decreasing asymptotically as they approach zero. However, this could not explain the flattening in young men, in whom rates were substantially higher than in women.

\section{International comparisons}

Has this phenomenon been seen elsewhere? Previous analyses of the flattening of the decline in mortality have mainly concentrated on age and sex effects in developed countries (England and Wales, United States, and Australia). Surprisingly little attention has been paid to inequalities. A comparison of mortality by educational level and occupational class in six European countries (Finland, Sweden, Norway, Denmark, England and Wales, and Italy) showed that the decline in mortality among socially disadvantaged people was
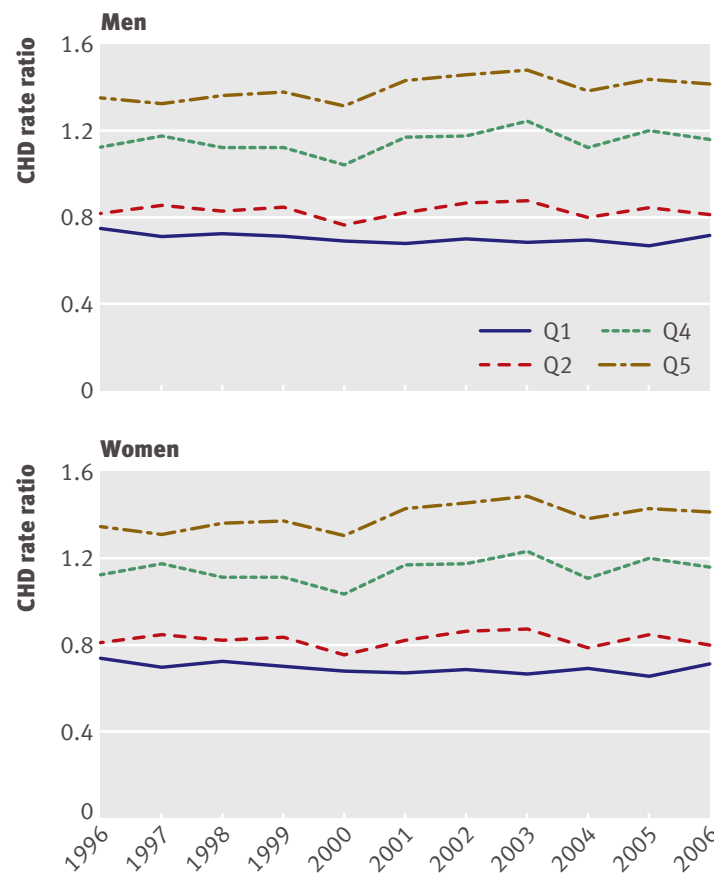
ratios (European standardised), Scotland 1996-2006, both sexes. Reference category is third fifth $\overline{\text { Fig } 5 \text { | Trends in coronary heart disease death deprivation rate }}$ 
Table 4 | Joinpoint analysis of coronary heart disease mortality trends by age and deprivation in Scotland 1996-2006: women aged 35 years and over

\begin{tabular}{|c|c|c|c|c|}
\hline $\begin{array}{l}\text { Age group (years) and } \\
\text { deprivation category }\end{array}$ & $\begin{array}{l}\text { Identified } \\
\text { periods }\end{array}$ & $\begin{array}{l}\text { No of deaths } \\
\text { (min-max) }\end{array}$ & $\begin{array}{l}\text { Rates per } 106 \\
(\min -\max )\end{array}$ & $\begin{array}{l}\text { Annual percentage change } \\
\qquad(95 \% \mathrm{Cl})\end{array}$ \\
\hline \multicolumn{5}{|l|}{ 35-54: } \\
\hline 1 and 2 (most affluent) & 1996-2006 & $4-20$ & 2-14 & $-6.54^{*}(-9.76$ to -3.20$)$ \\
\hline 3 & 1996-2006 & $15-28$ & $10-20$ & $-5.66^{*}(-9.11$ to -2.07$)$ \\
\hline 4 and 5 (most deprived) & $1996-2006$ & $25-57$ & $17-42$ & $-4.37^{\star}(-5.95$ to -2.75$)$ \\
\hline \multicolumn{5}{|l|}{ 55-64: } \\
\hline 1 and 2 (most affluent) & 1996-2006 & $14-60$ & 21-117 & $-11.42^{*}(-13.14$ to -9.66$)$ \\
\hline 3 & 1996-2006 & $43-84$ & $64-147$ & $-8.49^{*}(-10.17$ to -6.79$)$ \\
\hline 4 and 5 (most deprived) & 1996-2006 & $61-189$ & $99-299$ & $-6.22^{\star}(-7.92$ to -4.47$)$ \\
\hline \multicolumn{5}{|l|}{ 65-74: } \\
\hline \multirow{2}{*}{1 and 2 (most affluent) } & 1996-2001 & 93-195 & $225-441$ & $-7.52^{*}(-9.98$ to -4.98$)$ \\
\hline & $2001-6$ & $59-136$ & 133-294 & $-10.85^{\star}(-13.85$ to -7.74$)$ \\
\hline 3 & $1996-2006$ & $142-312$ & $275-604$ & $-7.47^{\star}(-8.85$ to -6.06$)$ \\
\hline \multirow{3}{*}{4 and 5 (most deprived) } & $1996-8$ & $346-458$ & $611-814$ & $1.49(-3.80$ to 7.07$)$ \\
\hline & 1998-2001 & 488-394 & 488-721 & $-7.97^{\star}(-13.16$ to -2.46$)$ \\
\hline & $2001-6$ & $192-325$ & $364-615$ & $-3.59^{*}(-5.01$ to -2.13$)$ \\
\hline \multicolumn{5}{|l|}{ 75-84: } \\
\hline \multirow{2}{*}{1 and 2 (most affluent) } & $1996-2000$ & $276-401$ & $1045-1320$ & $-4.18(-8.63$ to 0.49$)$ \\
\hline & $2000-6$ & $221-368$ & 719-1147 & $-7.74(-10.44$ to -4.95$)$ \\
\hline 3 & 1996-2006 & $314-527$ & 867-1544 & $-5.66^{*}(-6.73$ to -4.56$)$ \\
\hline \multirow{3}{*}{4 and 5 (most deprived) } & 1996-8 & $581-665$ & $1496-1819$ & $-5.67(-11.03$ to 0.01$)$ \\
\hline & 1998-2002 & $512-589$ & 1301-1649 & $-2.88(-5.90$ to 0.23$)$ \\
\hline & $2002-6$ & $342-488$ & 1019-1357 & $-6.45^{*}(-8.54$ to -4.30$)$ \\
\hline \multicolumn{5}{|l|}{$\geq 85:$} \\
\hline \multirow{2}{*}{1 and 2 (most affluent) } & $1996-2003$ & $308-441$ & $2548-3405$ & $-2.48^{*}(-4.18$ to -0.75$)$ \\
\hline & $2003-6$ & $276-432$ & $2588-3308$ & $-7.62^{\star}(-14.02$ to -0.74$)$ \\
\hline 3 & $1996-2006$ & $373-374$ & $2267-3567$ & $-2.55^{*}(-3.68$ to -1.40$)$ \\
\hline \multirow{3}{*}{4 and 5 (most deprived) } & $1996-2000$ & $389-453$ & 2906-3713 & $-4.70(-10.73$ to 1.73$)$ \\
\hline & $2000-4$ & $331-453$ & 2854-3308 & $1.31(-9.08$ to 12.90$)$ \\
\hline & $2004-6$ & $321-391$ & $2588-2738$ & $-11.67(-30.21$ to 1.79$)$ \\
\hline
\end{tabular}

*Significantly different from 0 .

young adults is not declining as fast as it is in older groups. Furthermore, deprived groups continue to have much higher smoking rates. ${ }^{11}$ In the United States, although cholesterol and blood pressure have improved in all socioeconomic groups, smoking and diabetes have actually increased among the more deprived groups. ${ }^{24}$

Much more probably, these changes in mortality reflect social gradients in unhealthy behaviour, lifestyle, and circumstances resulting in poor diet and high tobacco consumption leading to unfavourable levels of major risk factors for coronary heart disease.

\section{WHAT IS ALREADY KNOWN ON THIS TOPIC}

Mortality from coronary heart disease has been declining in Scotland and in most Western countries in the past 30 years

A recent slowing of this decline has been seen in young adults in the United States and in England and Wales

\section{WHAT THIS STUDY ADDS}

This preliminary analysis suggests that the flattening of the decline in coronary heart disease mortality in young men in Scotland is confined to deprived groups
These inequalities are persisting in spite of the widespread and constant health promotion and health prevention initiatives, which suggests substantial and continuing barriers to healthy changes. Increasing evidence suggests that younger and more deprived adults are less susceptible to preventive messages aimed at the general population. For example, lower income, less education, and lower self efficacy have all been shown to increase barriers to health promotion inter ventions. ${ }^{23}$ Furthermore, marginalised minority and low income groups may also receive less exposure to prevention messages on nutrition, exercise, and tobacco. ${ }^{25}$ Although a role for decreased uptake of treatments among the most deprived groups cannot be discarded, this is probably modest, as most premature deaths from coronary heart disease occur outside hospital, half of them in the absence of a previous diagnosis of cardiovascular disease..$^{2627}$

\section{Conclusions}

Premature death from coronary heart disease remains a potentially important contributor to social inequalities. Furthermore, the flattening of the decline in mortality from coronary heart disease among younger adults may be the first warning sign of worsening lifestyle choices and behaviours rather than deterioration of medical management of coronary heart disease. Unfortunately, large time series of measures of the prevalence of risk factors are not available for this population. This is an important priority for future research, to estimate the extent to which trends in major cardiovascular risk factors may explain inequalities in mortality from coronary heart disease. A better understanding of the complex interaction of causal risk factors and inequalities will also be crucial Marked deterioration in medical management of coronary heart disease seems implausible. Unfavourable trends in the major risk factors for coronary heart disease (smoking and poor diet) thus provide the most likely explanation for these apparent inequalities.

Contributors: SC, AR, and JC conceived the idea of the study. JB, TMCL, AR, $J C$, and DM procured the data. MO'F and JB did the main analyses and drafted the manuscript. All authors contributed to the final manuscript. SC is the guarantor.

Funding: MO'F is supported by the UK Medical Research Council. Competing interests: None declared.

Ethical approval: Not needed.

The findings and conclusions in this report are those of the authors and do not necessarily represent the views of ISD Scotland.

1 Critchley JA, Capewell S, Unal B. Life-years gained from coronary heart disease mortality reduction in Scotland: prevention or treatment? J Clin Epidemiol 2003;56:583-90.

2 Muller-Nordhorn J, Binting S, Roll S, Willich SN. An update on regional variation in cardiovascular mortality within Europe. Eur Heart J 2008;29:1316-26

3 Wilson A, Siskind V. Coronary heart disease mortality in Australia: is mortality starting to increase among young men? Int J Epidemiol 1995;24:678-84.

4 Tobias M, Sexton K, Mann S, Sharpe N. How low can it go? Projecting ischaemic heart disease mortality in New Zealand to 2015. N Z Med J 2006;119:U1932.

5 O'Flaherty M, Ford E, Allender S, Scarborough P, Capewell S. Coronary heart disease trends in England and Wales from 1984 to 2004: concealed levelling of mortality rates among young adults. Heart 2008;94:178-81. 
6 Ford ES, Capewell S. Coronary heart disease mortality among young adults in the U.S. from 1980 through 2002: concealed leveling of mortality rates. J Am Coll Cardiol 2007;50:2128-32.

7 Flegal KM, Carroll MD, Ogden CL, Johnson CL. Prevalence and trends in obesity among US adults, 1999-2000. JAMA 2002;288:1723-7.

8 Ezzati M, Oza S, Danaei G, Murray CJL. Trends and cardiovascular mortality effects of state-level blood pressure and uncontrolled hypertension in the United States. Circulation 2008;117:905-14.

9 Sproston K, Primatesta P. Health survey for England: risk factors for cardiovascular disease. London: Stationery Office, 2003.

10 Office for National Statistics. National food survey 2006. London: Department for Environment, Food and Rural Affairs, 2008.

11 Bromley C, Sproston K, Shelton N. The Scottish health survey 2003. Edinburgh: Scottish Executive Health Department, 2008.

12 Singh-Manoux A, Nabi H, Shipley M, Gueguen A, Sabia S, Dugravot A et al. The role of conventional risk factors in explaining social inequalities in coronary heart disease: the relative and absolute approaches to risk. Epidemiology 2008;19:599-605.

13 Waterhouse J, Muir C, Correa P, Powell J. Cancer incidence in five continents. Lyon: International Agency for Research on Cancer, 1976.

14 Scottish Executive. Scottish Index of Multiple Deprivation. 2008. www.scotland.gov.uk/Topics/Statistics/SIMD/.

15 Capewell S, Kendrick S, Boyd J, Cohen G, Juszczak E, Clarke J. Measuring outcomes: one month survival after acute myocardial infarction in Scotland. Heart 1996;76:70-5.

16 NHS National Services Scotland. Towards better data from Scottish hospitals. Edinburgh: ISD Scotland Publications, 2007

17 Norris RM, Wong PS, Dixon G, Morris N. The falling mortality from coronary heart disease: a clinicopathological perspective. Heart 1998;80:121-6.

18 Jordan H, Roderick P, Martin D. The Index of Multiple Deprivation 2000 and accessibility effects on health. J Epidemiol Community Health 2004;58:250-7.
19 Boyce J. Scottish Index of Multiple Deprivation. 2008 www.scotland. gov.uk/Resource/Doc/933/0059715.pdf.

20 Mackenbach JP, Bos V, Andersen O, Cardano M, Costa G, Harding S, et al. Widening socioeconomic inequalities in mortality in six Western European countries. Int J Epidemiol 2003;32:830-7.

21 Jemal A, Ward E, Anderson RN, Murray T, Thun MJ. Widening of socioeconomic inequalities in U.S. death rates, 1993-2001. PLoS One 2008;3:e2181.

22 Harald K, Koskinen S, Jousilahti P, Torppa J, Vartiainen E, Salomaa V. Changes in traditional risk factors no longer explain time trends in cardiovascular mortality and its socioeconomic differences. J Epidemiol Community Health 2008;62:251-7.

23 Bartley M, Fitzpatrick R, Firth D, Marmot M. Social distribution of cardiovascular disease risk factors: change among men in England 1984-1993. J Epidemiol Community Health 2000;54:806-14.

24 Kanjilal S, Gregg EW, Cheng YJ, Zhang P, Nelson DE, Mensah G, et al. Socioeconomic status and trends in disparities in 4 major risk factors for cardiovascular disease among US adults, 1971-2002. Arch Intern Med 2006;166:2348-55.

25 Benjamin-Garner R, Oakes JM, Meischke H, Stone EJ, Zapka J, Finnegan JR, et al. Sociodemographic differences in exposure to health information. Ethn Dis 2002;12:124-34.

26 Evans C, Chalmers J, Capewell S, Redpath A, Finlayson A, Boyd J, et al. "I don't like Mondays"-day of the week of coronary heart disease deaths in Scotland: study of routinely collected data. $B M$ J 2000;320:218-9.

27 Capewell S, Maclntyre K, Stewart S, Chalmers JW, Boyd J, Finlayson A, et al. Age, sex, and social trends in out-of-hospital cardiac deaths in Scotland 1986-95: a retrospective cohort study. Lancet 2001;358:1213-7.

Accepted: 7 April 2009 